\title{
O CUIDADOR EM SERVIÇO RESIDENCIAL TERAPÊUTICO (SRT) NO MUNICÍPIO DE SALVADOR-BA
}

\section{The caregiver in Residential Therapeutic Service (SRT) in the municipality of Salvador-BA}

Lúcio Silva Sande (UCSal)

Barbara Pompeu Christovam (UFF)

Informações do artigo

Recebido em 31/10/2017

Aceito em 09/06/2018

doi>: https://doi.org/10.25247/2447-861X.2019.n246.p54-68

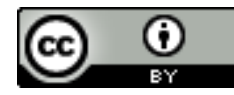

Esta obra está licenciada com uma Licença Creative Commons Atribuição 4.0 Internacional.

Como ser citado (modelo ABNT)

SANDE, Lúcio Silva; CHRISTOVAM, Barbara Pompeu. O cuidador em Serviço Residencial Terapêutico (SRT) no município de Salvador-BA. Cadernos do CEAS: Revista Crítica de Humanidades, Salvador, n. 246, jan./abr., p. 54-68, 2019. DOI: https://doi.org/10.25247/2447861X.2019.n246.p54-68

\begin{abstract}
Resumo
O Serviço Residencial Terapêutico é um instrumento imprescindível de direitos humanos no processo de desinstitucionalização psiquiátrica e retorno do indivíduo com transtorno mental ao meio social, para existir como ser de direitos e deveres. A casa se torna o núcleo das relações interpessoais e o ponto de partida ao início de vidas que foram tombadas por um modelo hegemônico e excludente. Um indivíduo em sofrimento psíquico não pode ter a sua vida pré-estabelecida por conta do preconceito e da intolerância. A rotina de um lar, a ida à feira, a união dos moradores para fazer um bolo de aniversário, entre outras ações, torna-se um exercício de cidadania ativa. O objetivo do estudo é conhecer como transcorre o processo do cuidar pelo profissional cuidador em Serviço Residencial Terapêutico no município de Salvador-BA. Trata-se de uma pesquisa descritiva qualitativa com abordagem etnográfica. Os atores dessa pesquisa são seis profissionais cuidadores de uma Residência Terapêutica no município de Salvador-BA. Os dados foram obtidos através de observação direta e sistemática por meio do diário de campo, roteiro de entrevista semiestruturada, com gravações das entrevistas através do uso gravador, direcionados aos profissionais envolvidos no processo do cuidar. Através desse estudo, fica claro e evidente que o cuidador é o principal ator que faz a ligação do morador ao meio extra-residência. Todo esse trabalho gera o fruto da ressocialização, fazendo do paciente, estigmatizado como louco, ameaçador, um morador comum, que pode fazer o que bem entender, sempre com supervisão e apoio profissional adequado.
\end{abstract}

Palavras-chave: Saúde Mental. Serviço de Saúde Mental. Cuidadores.

Abstract

The Residential Therapeutic Service is an essential instrument in the process of deinstitutionalization and return of the individual with mental disorder to the social environment. The house becomes the core of interpersonal relationships and the starting point at the beginning of lives that have been overtaken by a hegemonic and oppressive model. An individual with some kind of psychic suffering can not have his life pre-established because of prejudice and intolerance. The routine of a home, the going to the fair, the union of the residents to make a birthday cake, among other actions, become a humanistic and just therapy. The objective of the study is to know how the process of caring for the Caregiver in Residential Therapeutic Service takes place in the city of Salvador, Bahia. This is a qualitative descriptive research with an ethnographic approach. The actors of this research are six caregivers of a Therapeutic Residency in the city of Salvador-BA. The data were obtained through direct and systematic observation through the field diary, semi-structured interview script with recording of the interviews through the use of tape recorders directed at the professionals involved in the care process. Through this study, it is clear and evident that the caregiver is the main actor who makes the link of the resident to the extra-residence environment. All this work generates the fruit of resocialization, making the patient, stigmatized as crazy, threatening, an ordinary resident, who can do whatever he wants, always with adequate supervision and professional support.

Keywords: Mental Health. Mental Health Service. Caregivers. 


\section{Introdução}

A principal função de uma casa é abrigar e proteger. O homem só pode ser reconhecido verdadeiramente homem quando tem um lar, um abrigo. É na casa onde se concentra a força de integração dos pensamentos, lembranças e todas as suas perspectivas para lidar com a vida e as adversidades (SILVEIRA; SANTOS-JUNIOR, 2011; BACHELAR, 2008).

Desde a década de 40, no Brasil, a Psiquiatria iniciou o processo de reforma da sua clínica e assistência. A médica Nise da Silveira trouxe mudanças que refletiram diretamente no cenário da psiquiatria clássica. Ela mostrou, por exemplo, que a arte é uma ferramenta transformadora e que, agregada a outras ferramentas, serve de interlocução para o convívio e reconhecimento de pacientes esquizofrênicos perante a sociedade (MELO; FERREIRA, 2013).

O processo da reforma psiquiátrica brasileira inspirando-se também na experiência italiana, que prescreve a substituição dos hospitais psiquiátricos por instrumentos inseridos e articulados diretamente com a comunidade, com a garantia dos direitos e qualidade de vida para seus usuários (SILVEIRA; SANTOS-JUNIOR, 2011).

A Lei Federal Brasileira 10.216, homologada em 6 de abril de 2001, garante a progressiva substituição dos leitos em hospitais psiquiátricos com características manicomiais (instituições fechadas sem programas de reabilitação psicossocial efetivos, promotores da "cronificação" e marginalização das pessoas assistidas) por uma rede articulada e comunitária de atenção psicossocial (BRASIL, 2001).

Por isso, faz-se necessário o apoio integral dos serviços substitutivos, em especial, as Residências Terapêuticas, que consistem em um espaço de morar e viver na comunidade para egressos dos hospitais/manicômios de longa permanência (SILVEIRA; SANTOS-JUNIOR, 2011; BRASIL,1989).

As Residências Terapêuticas estão inseridas no espaço urbano, essas casas são destinadas à moradia de pessoas egressas de longo período de internação em hospitais psiquiátricos. Ao longo desses anos, esses indivíduos perderam vínculos familiares e sociais (BRASIL,1989 e 2005). 
A Portaria do Ministério da Saúde n 106/2000, estabelece, dentre outras atribuições, o processo de reabilitação buscando a progressiva inclusão ao meio social, o que não é uma missão fácil (SILVEIRA; SANTOS-JUNIOR, 2011; BRASIL, 1989).

O cuidado fornecido pelo Profissional cuidador nas Residências Terapêuticas garante à adaptação do indivíduo ao seu novo "lar", estabelecendo também, a ligação na apresentação, inserção e convívio ao meio social e resgate do laço familiar, quando possível (FASSHEBER; VIDAL, 2007).

O Serviço Residencial Terapêutico é um instrumento imprescindível no processo de desinstitucionalização e retorno do indivíduo com transtorno mental ao meio social. Essa mudança brusca de realidade não deve reproduzir um modelo retrógrado, o manicomial.

O cuidador é o vetor de maior importância para a transição do paciente confinado ao sujeito com direitos de retorno ao convívio em sociedade. A casa se torna o núcleo das relações interpessoais e o ponto de partida ao início de vidas que foram tombadas por um modelo hegemônico e opressor.

Todos os agentes que lutam para combater o estigma da "loucura" contribuem para o resgate de direitos que deixaram de existir a partir de um diagnóstico. A rotina de um lar, a ida à feira, a união dos moradores para fazer um bolo de aniversário, entre outras ações, tornam-se uma terapêutica humanística e justa.

Deste modo, o presente trabalho tem como finalidade conhecer como transcorre o processo do cuidar pelo profissional cuidador em Serviço Residencial Terapêutico no município de Salvador-BA, enfatizando o protagonismo do profissional cuidador e suas interfaces no processo do cuidar.

\section{Metodologia}

O estudo é caracterizado como uma pesquisa de abordagem qualitativa, do tipo descritiva de cunho etnográfico, pois possui uma capacidade reflexiva maior para lidar com o sujeito e os seus significados, práticas e fenômenos sociais que não podem ser mensurados, trabalhando assim, com valores e atitudes visíveis nas relações humanas (MINAYO, 2010). 
O estudo foi apreciado e aprovado pelo Comitê de Ética em Pesquisa - CEP, da Universidade Católica do Salvador, Parecer de no 1.978.200/2017 e aprovação da Coordenadoria de Gestão de Pessoas da Saúde da Secretaria Municipal da Saúde de Salvador, ofício no 146/2017. Foram obedecidos todos os preceitos éticos referentes à estudos com seres humanos, sendo assinado o Termo de Consentimento Livre e Esclarecido pelos participantes do estudo.

A pesquisa foi realizada em uma Residência Terapêutica situada na região central da cidade de Salvador-Ba, vinculada a um CAPS II na mesma região. Os atores do estudo são seis profissionais cuidadores que atuam na equipe da Residência Terapêutica. O estado da Bahia conta atualmente com 05 Serviços de Residência Terapêutica (SRT) todos localizados no município de Salvador, que no ano de 2014 apresentavam 115 beneficiários com cadastro ativo e receberam o auxílio Reabilitação Psicossocial (De volta pra casa) em Dezembro do mesmo ano (BRASIL; 2015).

A coleta de dados compreendeu o período de abril e maio de 2017 , onde os pesquisadores ficaram alocados no CAPS II, intermediando os encontros com os entrevistados junto à equipe técnica e visitas à Residência Terapêutica (RT).

Critérios de inclusão dos profissionais: Integração dos profissionais na Rede de Saúde Mental do município, que trabalham diretamente com moradores do RT; participar por livre e espontânea vontade do estudo; e assinar o Termo de Consentimento Livre e Esclarecido.

Antes do processo de coleta de dados, foi realizada uma reunião com os atores do estudo no CAPS II, local mais propício para o encontro. O pesquisador apresentou o projeto e convidou os profissionais, individualmente, para fazer parte do estudo, sendo marcado o horário mais acessível para o participante conceder a entrevista.

Os dados foram obtidos através de observação direta e sistemática por meio do diário de campo, roteiro de entrevista semiestruturada com gravação das entrevistas através do uso gravador direcionados aos profissionais envolvidos no processo do cuidar.

Uma vez tendo sido coletado, o material foi transcrito e ouvido múltiplas vezes, através de saturação de depoimentos, buscando fazer a melhor descrição possível das cenas observadas e narradas, afim de confirmar ou modificar as categorias previstas: O processo do 
cuidar em Serviço Residencial Terapêutico; O Profissional Cuidador em Serviço Residencial Terapêutico; O "lar" no encontro com a sociedade.

Os indivíduos participantes da pesquisa foram identificados de maneira a preservar o anonimato e confidencialidade, sendo codificados pela letra [C] de cuidador, seguindo das numerações de 1 a 6, que corresponde ao número total de cuidadores entrevistados.

\section{Resultados e discussão}

O processo do cuidar em Serviço de Residência Terapêutica (SRT)

A Residência Terapêutica traz consigo o desafio de aprimorar técnicas e práticas do cuidar. Trabalhar com egressos de manicômios, onde os direitos e o respeito eram deixados pra trás, é escrever cotidianamente experiências, vencer obstáculos e crescer como ser humano e profissional. É desconstruir o estigma da loucura e enxergar o morador como um ser pensante e capaz.

A pesquisa compreende um total de seis cuidadores da determinada RT. Desses seis: cinco homens e uma mulher; $66,6 \%$ se autodeclararam negros e 33,3\% pardos; 66,6\% referiram ensino médio completo e 33,3\% nível superior incompleto, pertencentes a faixa de idade entre 26 e 66 anos. Os cuidadores referem vínculos empregatícios distintos, 66\% se enquadram na Consolidação das Leis Trabalhistas (CLT), os outros 33,3\% em vínculo público municipal por meio de concurso.

A residência é composta por uma sala ampla com sofás, estante e televisão. São três quartos, um para a moradora do sexo feminino, os outros dois para os seis moradores do sexo masculino, cada um com três camas de solteiro, cômodas e guarda-roupas. Uma sala de jantar ampla com uma mesa, dois banheiros, cozinha com o registro de ponto, área de serviço e um terraço, que se torna uma área de convivência para os moradores. Não há um local de descanso específico para os cuidadores.

O Hospital Psiquiátrico trabalha com o método da disciplinarização, compreendendo que aqueles pacientes que não são considerados normais, precisam de um regime disciplinar que os torne normais. Dessa forma, existe uma segregação daqueles que oferecem algum tipo de risco à sociedade. O hospital passa a ser uma propriedade médica, e a loucura passa 
a ser considerada como doença. (CARVALHO; LINS, 2015). Os depoimentos que se seguem exemplificam a mudança no modelo de atenção.

Eu trouxe uma bagagem do hospital, mas a bagagem não foi boa, eu vim aprender mais na residência terapêutica, eu dei importância a esse trabalho [...] levei ele ao mundo, no hospital não, ficavam todos presos, coisas horríveis, na casa não, eles têm a autonomia deles. [ $\left.\mathrm{C}_{1}\right]$

Lá parecia uma prisão [...] aqui começaram a viver, aqui teve liberdade, teve tudo [...] Hospital parece uma prisão, muito diferente daqui [...] aqui eles freqüentam tudo. [C4]

É notório que todos os cuidadores quando mencionam os Hospitais Psiquiátricos comparam o cuidado que era prestado aos moldes manicomiais, diferente do que hoje eles podem proporcionar na Residência Terapêutica. Mudança significativa para a vida do morador, antes paciente, e do cuidador que desempenha um trabalho de melhor qualidade e respeito, como referiram.

Após a Reforma Psiquiátrica, lei 10.216/2001, instrumentos substitutivos foram criados como forma de amparar os indivíduos internados nos hospitais psiquiátricos. ${ }^{4} \mathrm{O}$ Serviço Residencial Terapêutico (SRT) surge como um suporte adequado para abrigar os exinternos e dar-Ihes uma nova perspectiva de vida fora de um manicômio, onde não existia o menor vínculo com o convívio em sociedade (BRASIL, 2001).

Foi muito trabalhoso pra trazer eles para a sociedade [...] até hoje é um aprimoramento, a cada dia que passa. [C1]

A princípio a gente fica um pouco receoso, a respeito de tudo, como eles vão receber [...] o contato foi bom, o convívio é gratificante. [C2]

Eu já trabalhava no hospital psiquiátrico, dai houve a oportunidade [...] foi tranquilo, esses moradores eu já trabalhava com eles nos sanatórios. [C3]

Não sinto dificuldade alguma. [C5]

A casa deve atender às padronizações da Portaria do MS nº 3.090 de 23 de Dezembro de 2011, para que possa ser habitada pelos novos moradores que merecem e precisam de um suporte adequado e especializado. É nesse momento que o cuidador exerce papel de 
importância na fase adaptativa dessas pessoas, sendo imprescindível o seu papel na prática do cuidar (FASSHEBER; VIDAL, 2007).

Os moradores exercitam o respeito, a confiança e o cuidado ao próprio cuidador. Em tudo que acontece eles se reportam aos cuidadores, que são os principais elos, intermediando e solucionando problemas de ordem de convivência no ambiente doméstico, clínico e constituem a principal referência em serviço de saúde que é o CAPS.

Antes de falar com a psicóloga, ele fala com a cuidadora, antes de sentir qualquer dor, passa para a cuidadora [...] [C1]

A gente tem que conversar antes, uma tricotomia, higiene pessoal, tudo aqui é negociado, ter essa confiança com a gente, têm outros que não aceitam logo no momento. [C2]

O individualismo deve ser levado em conta no processo de adequação à RT. A equipe multiprofissional deve ficar atenta à singularidade de cada morador (FASSHEBER; VIDAL, 2007).

Eles sabem fazer as coisas na casa, eles colaboram, não podem ficar só deitados, eles sabem tudo. [C1]

No ambiente hospitalar, eles são tratados de forma igualitária. Existem horários para o banho, para o almoço, lanches e janta. No ambiente domiciliar, a atenção deve ser voltada para uma nova rotina, nunca antes vivida, dessa forma, a sua recuperação não será moldada e sim poderão construir um novo modo de viver (MELO; FERREIRA, 2013; BRASIL, 1989).

Tudo que eles compram trazem nota fiscal, tudo isso é parte do nosso trabalho. [C1]

Todos eles têm autonomia, vai, compra o que quer, passeiam [...] [C2]

O plano de cuidado individualizado é fundamental na transição hospital-residência. O espaço de cada morador é respeitado, também seus anseios e desejos. O cuidador busca agradá-los de todas as formas, do bolo que eles mais gostam até o programa de TV que mais agrada.

Os moradores que hoje vivem em RT não têm vínculo com a sua família de origem. Muitos foram abandonados ainda pequenos nos Hospitais Psiquiátricos ou a família os abandonou no processo terapêutico. O fardo de ter uma pessoa com transtornos mentais na 
família e todo o estigma social são fatores desencadeantes do processo de abandono (BRASIL, 2005; AREJANO et al, 2003; FASSHEBER; VIDAL, 2007).

Por isso, os moradores veem os cuidadores como pais, invocando seus referenciais de família. Mediante tamanha importância na prática do cuidado, deve-se atentar à importância desses profissionais (PALOMBINI et al, 2010).

O profissional cuidador em Serviço de Residência Terapêutica

O funcionamento de uma rede eficaz composta por serviços alternativos à hospitalização é fundamental para a prática da Reforma Psiquiátrica. Sem esses serviços, seria impossível a retirada dos pacientes dos hospitais psiquiátricos para o meio extrahospitalar. A desinstitucionalização deve propor alternativas mais humanizadas para a prática do cuidado (BRASIL, 2004 e 2011).

O Profissional cuidador torna-se produtor das novas práticas, o que favorece o surgimento de novos modelos de relação entre os sujeitos envolvidos. Deve-se pensar também, na superação das práticas impostas pelo hospital psiquiátrico e o que deve ser desenvolvido pelo SRT (PALOMBINI et al, 2010).

[...] eu trabalho com o colega hoje, se ele não dá continuidade ao trabalho, influi, nunca vai pra frente, o morador está querendo que aquele colega continue aquele trabalho [...] eles são notados, eles gostam disso, tem que ser notados, dá atenção demais. [C1]

Na visita à residência, a recepção é a melhor possível. Eles gostam de agradar o visitante, mostram cada canto da residência e suas especificidades. O convívio com os outros moradores também é pacífico, sempre com altos e baixos, como todas as relações em comunidade. A desenvoltura e espontaneidade com as tarefas domésticas são desenvolvidas e aprimoradas cotidianamente.

A conquista da autonomia é o principal objetivo de uma RT articulado ao cuidado que é produzido pelo cuidador. O novo espaço deve ser a conquista da individualidade, o sujeito deve ter vontade própria, os seus anseios devem ser respeitados. Sendo assim, esse modelo extra-hospitalar contribui para a construção de uma nova identidade (FASSHEBER; VIDAL, 2007). 
A casa é o ponto de partida para que o sujeito construa novos projetos individuais. Os moradores da casa formam uma rede de apoio aos seus ideais. Ocorre a construção de novos vínculos afetivos (FASSHEBER; VIDAL, 2007) evidenciando as necessidades particulares e peculiaridades de cada indivíduo inserido no serviço (BRONDANI et al, 2010).

O ambiente deve ser condicionado à ludicidade. A criatividade expressa anecessidade da sensibilidade no cuidar. Isso pode ser visto nas simples ações realizadas na casa. O lúdico se manifesta pelas iniciativas do cuidador, diretamente ligado a sua postura na prestação do cuidado (PALOMBINI et al, 2010; BRONDANI et al, 2010).

O cuidado com a dimensão afetiva está manifestado pela ligação entre um indivíduo ao outro. Um olhar, um sorriso, um gesto. Manifestando assim, a preocupação e qualidade do cuidado a esses indivíduos que carecem de uma atenção especial. A paciência também é uma ferramenta auxiliar importante (BRONDANI et al, 2010).

A colaboração de outras pessoas no processo do cuidar, como família, amigos, comunidade e outros profissionais de saúde, torna o cuidado na residência uma tarefa mais equilibrada, garantindo melhor qualidade no cuidado, diminuindo a sobrecarga física, emocional e social. A construção de uma rede solidária é uma das estratégias para o auxílio no desenvolvimento de práticas do cuidar em domicílio (PALOMBINI et al, 2010).

Onde eles habitam, a comunidade já conhece eles, fica mais fácil de ter esse contato com a sociedade. [C2]

Cada novo morador encara a transição do hospital para uma residência de forma particular, produzindo novos significados em relação ao novo lar. Uns têm apreensão, outros consideram algo magnífico. A liberdade passa a ser um contexto construído por cada morador (FASSHEBER; VIDAL, 2007).

Está sendo um projeto muito bom, eu gosto muito do meu trabalho. [C1]

A RT se configura em um espaço de ações coletivas, mobilização e invenções de novos modos de reprodução social, das pessoas em suas trocas sociais e nos grupos e organizações, para o fortalecimento dos bens públicos e interesses solidários (OLIVEIRA, W et al, 2017).

Eu gosto muito, foi daí que eu decidi ser Enfermeiro. [C 3 ] 
A satisfação profissional vai além da remuneração financeira. Os principais produtos do cuidado produzido no SRT é a melhora do quadro clínico dos indivíduos, a adaptação, o acolhimento e o conforto para o usuário, principalmente quando se consegue uma nova vinculação com a família, fazendo dele um ser integrante e atuante na sociedade (SILVEIRA; SANTOS-JUNIOR, 2011).

O lar no encontro com a sociedade

A Reforma Psiquiátrica trouxe diversas indagações acerca de como lidar com esse novo indivíduo regado de direitos e anseios próprios. A redução dos leitos nos hospitais psiquiátricos e a condição cronificante como são rotulados os egressos fez surgir a necessidade de estruturas residenciais extra-hospitalares (FURTADO, 2006).

Existiam muitas críticas quando saía com eles, riam deles, não sabiam nem falar direito [...] estão aptos para qualquer lugar, já foram pra teatro, cinema, praia, almoçam maravilhosamente, a carne não sai do prato, cortam numa boa, comemos caviar. [C1]

O lar é o local mais importante para o desenvolvimento e a constituição do sujeito. A sua finalidade é decisiva na formação da subjetividade, sendo o polo integrador de vivências, pensamentos, lembranças e sonhos. Sem esses elementos o indivíduo se torna disperso (BRANDÃO, 2002; PITTA et al, 2015).

Existe a preocupação dos cuidadores também proporcionarem conforto e comodidade aos moradores. O ambiente tem que ser o mais agradável possível, pois a casa é a identidade das pessoas que nela habitam; se ela não for agradável o suficiente para satisfazer às necessidades dos moradores, se tornará um problema.

É uma casa bem antiga, a gente tem dificuldade, dificuldade de iluminação, banheiro sem energia, hidráulica, isso acaba afetando o bem estar deles [C2]

A casa constitui um espaço que assegura a afirmação da singularidade do seu morador. A morada representa uma barreira de proteção do mundo e do que se passa fora dela. Esse espaço fora do lar pode ser considerado ameaçador e complexo, principalmente para uma pessoa com transtorno psíquico grave (BRASIL, 2004; FURTADO, 2006). 
A quantidade de cuidadores é pequena, tendo cuidador, cuida, aquele que quer cuidar, não me arrependo de jeito nenhum de onde eu estou. [ $\left.C_{1}\right]$

É imprescindível que exista uma quantidade suficiente de moradores para trabalhar nas residências, porque eles também são responsáveis pelas tarefas domésticas, controle dos suprimentos, acompanhamento dos moradores às consultas médicas, atividades no CAPS e de lazer. Além da sobrecarga de trabalho, há necessidade de manter equilíbrio físico e mental.

Eu tenho a parte do tempo maior na cozinha e ao mesmo tempo estou dando atenção a eles. $\left[C_{1}\right]$

A maior dificuldade é quando um morador precisa ficar hospitalizado, a gente tem que acompanhar, acontece de alguns plantões ficar só um cuidador, teve gente que dobrou, nossa equipe é pequena. [C2]

A vivência em um lar é uma prática transformadora na dinâmica das relações interpessoais. Existe uma transformação de quem passa do lugar do louco-morador ao morador-louco. Não se deve pensar no indivíduo deixando de ser louco, mas, a partir desse novo contexto, identificando o sujeito como morador (PITTA et al, 2015; LIVIERES; SILVA, 2006).

Eles tão envelhecendo, as questões clínicas vêm também, eles vão envelhecer, acontece de ficar internado e a gente não ter esse suporte de cuidadores para revezar. [C2]

Aqui a gente busca essa ressocialização de fato [...] não é deixar no hospital, dá medicamentos [...] tem uma evolução pra melhor, a questão da Reforma Psiquiátrica [...] Aqui é uma relação muito mais próxima, aqui a gente faz de tudo pra que eles se sintam em casa, a casa é sua! [C5]

Os cuidadores deixam evidente que o cuidado fornecido na RT é um marco diferencial, tendo em vista os instrumentos de Saúde Mental da contemporaneidade. A transição de um ambiente composto por pessoas psiquiátricas, para a leveza de um lar harmônico não é uma tarefa fácil, mas é possível. A confiança e a relação de respeito com o próximo é imprescindivel. 
O QualityRights ${ }^{1}$ traz uma abordagem no que concerne à capacidade de avaliação e ao estímulo de melhorias dos serviços, plano político e conquista de direitos. A sua implementação tem como objetivo alcançar mudanças voltadas para a assistência social, vidas mais seguras e agradáveis, aumentando a autonomia das pessoas (PITTA, 2011; OMS, 2012).

Nascem novos tempos de luta pela saúde no país, a construção de um novo conceito de saúde, ampliado e transformador, que é o da saúde como cidadania, democracia e qualidade de vida (OLIVEIRA, W et al, 2017).

\section{Considerações finais}

O Serviço Residencial Terapêutico mostrou-se um instrumento inovador junto à Reforma Psiquiátrica. A sua aplicabilidade evidencia o quão é importante para o processo de retorno do indivíduo à comunidade, quando egresso de hospitais psiquiátricos, em encontro com a sociedade e a valorização da vida em seu largo espectro.

O cuidador é a peça-chave fundamental na interlocução do morador com o meio social e atividades cotidianas. Faz-se necessário o aprimoramento das técnicas do cuidar, assim como a melhoria nas condições de trabalho e infraestrutura no geral.

A principal dificuldade encontrada ao longo da pesquisa foi a coleta de dados através de entrevistas. A inflexibilidade no horário dos cuidadores, por trabalharem em escala de turnos, e tendo um cuidador de férias, foi necessária a incessante busca de um momento em comum para o pesquisador e cuidador.

A equipe do CAPS se mostrou empenhada em contribuir para com a pesquisa, esquematizando encontros e visitas à RT, priorizando a importância do espaço do morador e evitando a sensação de invasão de privacidade por parte do morador e cuidador.

Através desse estudo, fica claro e evidente que o cuidador é o principal ator que faz a ligação do morador ao meio extra-residência. Todo esse trabalho gera o fruto da importância

1 QualityRights fornece aos países informações e ferramentas práticas para avaliar e melhorar os padrões de qualidade e direitos humanos em instituições de saúde mental e assistência social. 
da ressocialização, fazendo do paciente, estigmatizado como louco, ameaçador, um morador comum, que pode fazer o que bem entender, sempre com supervisão e apoio profissional adequado.

É necessário o investimento e o aprimoramento das Políticas Públicas, no que tange à implantação e implementação de novos Serviços de Residência Terapêutica, bem como o investimento no desenvolvimento de outras pesquisas que visem ao aprimoramento da prática do cuidar pelo profissional cuidador, assim como a sua devida valorização de parte institucional, econômica e social.

\section{Referências}

AREJANO, CB; PADILHA, MICS; ALBUQUERQUE, GL. Reforma Psiquiátrica: uma analítica das relações de poder nos serviços de atenção à saúde mental. Rev. Bras. Enferm., v. 5, n. 56, p. 549-54, 2003. [Acesso em 10 de Set de 2016] Disponível em: http://www.scielo.br/pdf/reben/v56n5/a16v56n5.pdf

BACHELAR, G. A poética do habitat. São Paulo: Martins Fontes, 2008.

BRANDÃO, L. A casa subjetiva. São Paulo: Edição Perspectiva, 2002. 176p.

BRASIL. Diário do Congresso Nacional Secção I. Projeto de Lei n⿳0 3.667, de 29 de setembro de 1989 (Do Sr. Paulo Delgado) - Dispõe sobre a extinção progressiva dos manicômios e sua substituição por outros recursos assistenciais e regulamenta a internação psiquiátrica compulsória. [Acesso em: 30 de Ago 2016] Disponível em:

http://imagem.camara.gov.br/lmagem/d/pdf/DCD29SET1989.pdf\#page=30

BRASIL. Ministério da Saúde. Lei de n. 10.216, de 06 abr. 2001. Dispõe sobre a proteção e os direitos das pessoas portadoras de transtornos mentais e redireciona o modelo assistencial em saúde mental. Diário Oficial da República Federativa do Brasil, Poder Executivo. Brasília (DF), 9 abr. 2001a. [Acesso em: 30 de Ago 2016] Disponível em: http://www.planalto.gov.br/ccivil_03/leis/LEIS_2001/L10216.htm

BRASIL. Ministério da Saúde. Reforma psiquiátrica e política de saúde mental no Brasil. Documento apresentado à Conferência Regional de Reforma dos Serviços de saúde Mental: 15 anos depois de Caracas. Brasília: OPAS/Ministério da Saúde, 2005.

BRASIL. Ministério da Saúde. Residências Terapêuticas: o que são, para que servem? Brasília: Ministério da Saúde, 2004b. [Acesso em 27 de Ago de 2016] Disponível em: http://www.maringa.pr.gov.br/cisam/residencia_terepeutica.pdf

BRASIL. Ministério da Saúde. Saúde Mental em Dados. 12, ano 10, nº 12. Informativo eletrônico. Brasília: Outubro de 2015. [Acesso em 04 de Ago de 2016]. Disponível em: 
http://www.mhinnovation.net/sites/default/files/downloads/innovation/reports/Report_12edicao-do-Saude-Mental-em-Dados.pdf

BRASIL. Portaria nº 3.090, de 23 de Dezembro de 2011. Dispõe sobre o repasse de recursos de incentivo de custeio e custeio para implementação dos Serviços Residenciais Terapêuticos (SRT). Ministério da Saúde - Gabinete do Ministro. [Acesso em 30 de Ago de 2016] Disponível em:

http://www.saude.campinas.sp.gov.br/saude/lista_legislacoes/legis_2012/U_PT-MS-GM3090-REP_231211.pdf

BRASIL. Práticas de cuidados produzidas no serviço de residências terapêuticas: percorrendo os trilhos de retorno à sociedade. [online]. Campina Grande: EDUEPB, 2011. 320 p. ISBN 978- 85-7879-063-9. SciELO Books. [Acesso em: 20 de Ago 2016] Disponível em: http://static.scielo.org/scielobooks/pgwpg/pdf/silveira-9788578791230.pdf

BRASIL. Que eles falem por si: relatos dos profissionais sobre a experiência nas residências terapêuticas. Revista Ciência \& Saúde Coletiva, 16 (4): 2089-2098, 2011. [Acesso em 10 de Set de 2016] Disponível em: http://www.redalyc.org/pdf/630/63018472008.pdf

BRONDANI; CM; BEUTER, M; ALVIM, NAT; SZARESKI, C; ROCHA, LS. Cuidadores e estratégias no cuidado ao doente na internação domiciliar. Texto Contexto Enfermagem, Florianópolis, $2010 \mathrm{Jul}-S e t ;$ 19(3): 504-10. [Acesso em 10 de Out de 2017] Disponível em: http://www.scielo.br/pdf/tce/v19n3/a12v19n3

CARVALHO, JD; LINS, CBA. (2015, junho). Um Hospital Geral e suas concepções de loucura. Revista Latino-americana de Psicopatologia Fundamental, 18(2), 383-393.

FASSHEBER, VB; VIDAL, CEL. Da tutela à Autonomia: Narrativas e Construções do Cotidiano em uma Residência Terapêutica. Revista Psicologia, Ciência e Profissão, 2007, 27 (2), 194-207. [Acesso em 20 de Set de 2016] Disponível em:

http://www.redalyc.org/pdf/2820/282021756003.pdf

FURTADO, JP. Avaliação da situação atual dos Serviços de Residenciais Terapêuticas no SUS. Revista Ciênc Saúde Coletiva. 2006. [Acesso em 29 de Out de 2016] Disponível em: http://ww.scielo.br/pdf/csc/v11n3/30993.pdf

LIVIERES, CF; SILVA ALA. O projeto moradia assistida do centro de atenção psicossocial: de uma questão clínica a outra. Revista Escola de Enfermagem USP, 2006; 40(2): 188-95. [Acesso em 7 de Out de 2016] Disponível em: http://www.scielo.br/pdf/reeusp/v4on2/05.pdf

MELO, W; FERREIRA, A. P. (2013, dezembro). Clínica, pesquisa e ensino: Nise da Silveira e as mutações na Psiquiatria Brasileira. Revista Latino-americana de Psicopatologia

Fundamental, 16(4), 555-569. [Acesso em: 27 de Ago 2016] Disponível em: http://www.scielo.br/pdf/rlpf/v16n4/05.pdf

MINAYO, MCS. O desafio do conhecimento: pesquisa qualitativa em saúde. 12. ed. SP: Hucitec, 2010. 
OLIVEIRA, W; PITTA, A; AMARANTE, P. Direitos Humanos e Saúde Mental. Capítulo 4: 107-133. Editora Hucitec, São Paulo, 2017.

PALOMBINI, AL; BARBOZA, RP; FICK, TK; BIMKOWSKI, G. Cuidando do cuidador: da demanda de escuta a uma escrita de si. Revista Latino-americana de Psicopatologia Fundamental, São Paulo, v. 13, n.2, p. 253-264, jun. 2010. [Acesso em 13 de Set de 2016] Disponivel em: http://www.scielo.br/pdf/rlpf/v13n2/07.pdf

PITTA, AMF. Um balanço da reforma psiquiátrica brasileira: instituições, atores e políticas. Ciência e Saúde Coletiva, Rio de Janeiro, v.16, n.12, p. 4579-4589.2011.

PITTA, AMF; COUTINHO, DM; ROCHA, CCM. Direitos humanos nos Centros de Atenção Psicossocial do Nordeste do Brasil: um estudo avaliativo, tendo como referência o QualityRights - WHO. Revista Saúde em Debate, Rio de Janeiro, V.39, N.106, P. 760771.2015. [Acesso em 10 de Out de 2016] Disponível em: http://www.scielo.br/pdf/sdeb/v39n106/0103-1104-sdeb-39-106-0076o.pdf

WORLD HEALTH ORGANIZATION (WHO). WHO QualityRights tool kit to assess and improve quality and human rights in mental health and social care facilites.

Geneva:WHO, 2012. [Acesso em 29 de Out de 2016] Disponível em: http://apps.who.int/iris/bitstream/10665/70927/3/9789241548410_eng.pdf.

\section{Dados dos autores}

Lúcio Silva Sande

Bacharel em Enfermagem pela Universidade Católica do Salvador (UCSal). Pesquisador do Núcleo de Estudos em Saúde e Cidadania, UCSal - NESC/CNPq. E-mail: lucio.sande@hotmail.com.

\section{Barbara Pompeu Christovam}

Doutora em Enfermagem pela EEAN/UFRJ; Pós-doutorado em Políticas Sociais e Cidadania pela UCSal. Pesquisadora e Professora da Universidade Federal Fluminense, Vice-líder do Grupo de Estudos e Pesquisas em Cidadania e Gerência na Enfermagem, NECIGEN/UFF. Representante do Brasil na Rede Internacional de Gestão do Cuidado da OPAS/OMS. E-mail: barbarachristovam@id.uff.br 